\title{
Micronuclei induced by reverse transcriptase inhibitors in mononucleated and binucleated cells as assessed by the cytokinesis-block micronucleus assay
}

\author{
Eloir D. Lourenço ${ }^{1}$, Viviane S. do Amaral ${ }^{2}$, Mauricio Lehmann ${ }^{1,2}$, Rafael R. Dihl' ${ }^{2}$, Virginia M. Schmitt ${ }^{3}$, \\ Kênya S. Cunha ${ }^{4}$, Maria L. Reguly ${ }^{2}$ and Heloisa H.R. de Andrade ${ }^{5}$ \\ ${ }^{1}$ Programa de Pós-Graduação em Diagnóstico Genético e Molecular, Universidade Luterana do Brazil, \\ Canoas, RS, Brazil. \\ ${ }^{2}$ Laboratório da Toxicidade Genética, Programa de Pós-Graduação em Genética e Toxicologia Aplicada, \\ Universidade Luterana do Brazil, Canoas, RS, Brazil. \\ ${ }^{3}$ Laboratório de Biologia Molecular, Instituto de Pesquisas Biomédicas, Pontifícia \\ Universidade Católica do Rio Grande do Sul, Porto Alegre, RS, Brazil. \\ ${ }^{4}$ Laboratório de Genética Toxicológica, Departamento de Bioquímica e Biologia Molecular, \\ Instituto de Ciências Biológicas, Universidade Federal de Goiás, Goiânia, GO, Brazil. \\ ${ }^{5}$ Laboratório de Estomatologia, Hospital de Clínicas de Porto Alegre, \\ Universidade Federal do Rio Grande do Sul, Porto Alegre, RS, Brazil.
}

\begin{abstract}
This study evaluated the clastogenic and/or aneugenic potential of three nucleoside reverse transcriptase inhibitors (zidovudine - AZT, lamivudine - 3TC and stavudine - d4T) using the cytokinesis-block micronucleus (CBMN) assay in human lymphocyte cultures. All three inhibitors produced a positive response when tested in binucleated cells. The genotoxicity of AZT and 3TC was restricted to binucleated cells since there was no significant increase in the frequency of micronuclei in mononucleated cells. This finding indicated that AZT and 3TC caused chromosomal breakage and that their genotoxicity was related to a clastogenic action. In addition to the positive response observed with $\mathrm{d} 4 \mathrm{~T}$ in binucleated cells, this drug also increased the frequency of micronuclei in mononucleated cells, indicating clastogenic and aneugenic actions. Since the structural differences between AZT and 3TC and AZT and d4T involve the 3' position in the 2'-deoxyribonucleoside and in an unsaturated 2',3',dideoxyribose, respectively, we suggest that an unsaturated 2', 3', dideoxyribose is responsible for the clastogenic and aneugenic actions of d4T.
\end{abstract}

Key words: lamivudine, micronucleus assay, stavudine, transcriptase inhibitors, zidovudine.

Received: October 7, 2009; Accepted: June 2, 2010.

Nucleoside reverse transcriptase inhibitors (NRTIs) are widely used to treat human immunodeficiency virus (HIV) infections and prolong the survival of HIV-infected patients. NRTIs are incorporated into viral DNA, leading to blockade of the viral reverse transcriptase nucleotide binding site and the termination of replication (Huang and Jolicoeur, 1990).

Zidovudine (3'-azido-3'-deoxythymidine; AZT), lamivudine (2'-deoxy-3'-thiacytidine; 3TC) and stavudine (2',3'-didehydro2',3'-dideoxythymidine; d4T) are nucleoside reverse transcriptase inhibitors (NRTIs). Typically, AZT and 3TC are administered as part of highly active antiretroviral therapy protocols. The genotoxic manifesta-

Send correspondence to Rafael R. Dihl. Laboratório da Toxicidade Genética, Programa de Pós-Graduação em Genética e Toxicologia Aplicada, Universidade Luterana do Brazil, Prédio 22, $4^{\circ}$ andar, Gabinete 1, Av. Farroupilha 8001, 92425-900 Canoas, RS, Brazil. E-mail: rafael.rodrigues@ulbra.br. tions of AZT include mutagenesis, chromosomal aberrations and telomere shortening (Huang and Jolicoeur, 1990; Dobrovolsky et al., 2005). The major mechanisms of mutation induction by AZT involve large interstitial deletions and mitotic recombination (Mittelstaedt et al., 2004).

Based on the mechanism of AZT action, the genotoxicity of NRTIs has been defined as a complex, intricate network of events that may lead to large-scale genomic instability as a result of drug incorporation into DNA (Olivero et al., 1997). Numerous reports based on experiments in vitro (cultured cells) and in vivo have described the induction of micronuclei by AZT (Gonzalez-Cid and Larripa, 1994; Agarwal and Olivero, 1997; Aruna and Jagetia, 2001; Wutzler and Thust, 2001; Kirsch-Volders et al., 2002; Olivero, 2007; Guimarães et al., 2008). However, only a few studies have investigated the genotoxic potential of 3TC and d4T (Schilling et al., 1995; Von Tungeln et al., 2002; Carter et al., 2007; Kaur and Singh, 2007). 
In this study, we investigated the clastogenic and/or aneugenic potential of AZT, 3TC and d4T using the cytokinesis-block micronucleus (CBMN) assay in human lymphocyte cultures. We also examined the structure-activity relationships for the mutagenicity of these compounds. Previous studies suggested that the assessment of micronuclei in mononucleated cells might be an interesting additional parameter in the CBMN assay since these cells can reflect aneugenic effects (Elhajouji et al., 1998; Rosefort et al., 2004). For this reason, we analyzed both mononucleated and binucleated cells in an attempt to detect differences in the responses to these three NRTIs and their spectrum of chromosomal mutagenicity.

Peripheral blood lymphocytes were obtained by venipuncture from two healthy females (26 and 29 years of age, referred to as donors 1 and 2, respectively) and one healthy male (24 years of age, donor 3 ). All of the donors were non-smokers who had not recently been exposed to significant ionizing radiation or mutagens known to induce micronuclei. None of the donors had any structural or numerical chromosomal alterations in their karyotypes. For each donor, one series of cultures was prepared with two parallel cultures ('duplicates') for every concentration of mutagen tested. Whole blood cultures were done as recommended by Migliore et al. (1989). For each culture, $0.8 \mathrm{~mL}$ of heparinized blood samples was added to $8 \mathrm{~mL}$ of RPMI1640 medium (Sigma Chemical Co., St. Louis, MO, USA) containing $10 \%$ fetal calf serum, $1 \%$ penicillin/streptomycin and $80 \mu \mathrm{L}$ of phytohemaglutinin $(10 \mu \mathrm{L} / \mathrm{mL})$ (PHA, Gibco, New Zealand).

The NRTIs were purchased from IQUEGO (Indústria Química de Goiás, Goiânia, GO, Brazil) and included zidovudine (3'-azido-3'-deoxythymidine or AZT; CAS no. 30516-87-1), lamivudine (2'-deoxy-3'-thiacytidine or 3TC; CAS no. 134678-17-4) and stavudine (2',3'-didehydro2'-,3'-dideoxythymidine or d4T; CAS no. 3056-17-5). Bleomycin (BLM, Blenoxane ${ }^{\mathbb{B}}$; Bristol Myers Squibb S.A., São Paulo, SP, Brazil) was used as a positive control. All of the compounds were diluted in sterile distilled water, which was also used as a negative control.

Forty-eight hours before harvesting, the cell cultures were supplemented with NRTIs, BLM or sterile distilled water, all of which were sterilized by filtration through a Sartorius 0.22-mm pore filter. After an additional $44 \mathrm{~h}$, all of the cultures were supplemented with $6 \mu \mathrm{g}$ of cytochalasin B/mL (cyt-B; Sigma) to prevent cells that had completed one nuclear division from undergoing cytokinesis. The use of cyt-B allowed the accumulation of virtually all dividing cells at the binucleate stage, regardless of their degree of synchrony. The total incubation time for all cultures was $72 \mathrm{~h}$ at $37^{\circ} \mathrm{C}$. After incubation, the cells were exposed to a hypotonic solution $(0.075 \mathrm{M} \mathrm{KCl})$ for $5 \mathrm{~min}$. This procedure preserved the cytoplasm and allowed the assignment of micronuclei to their corresponding main nucleus. The cells were fixed in methanol:glacial acetic acid (3:1, $\mathrm{v} / \mathrm{v}$ ), spotted onto clean microscope slides, air-dried, and stained with Giemsa stain. Micronucleated cells were analyzed by light microscopy and scored for binucleated and mononucleated lymphocytes, with micronuclei being scored based on standard recognition criteria proposed by Fenech et al. (2003). To avoid scorer bias, the slides were coded so as to blind the scorer to the sample. For each culture, 500 binucleated and 500 mononucleated cells were examined. The micronuclei frequencies for the control and NRTI-treated cultures are shown in Table 1. Since there were no significant differences between the data for duplicate cultures these results were pooled to yield 3,000 binucleated and mononucleated cells for each concentration.

The nuclear division index (NDI) was used as a parameter for cytotoxicity. For this, 1,000 cells per donor were screened at $400 \mathrm{X}$ magnification to determine the frequency of cells with one, two, three or four nuclei, after which the NDI was calculated according to the formula:

$$
\mathrm{NDI}=\frac{[\mathrm{M} 1+2(\mathrm{M} 2)+3(\mathrm{M} 3)+4(\mathrm{M} 4)]}{\mathrm{N}}
$$

where M1 to M4 represent the number of cells with 1-4 nuclei and $\mathrm{N}$ is the total number of cells scored. Since nuclear divisions are asynchronous in CBMN-blocked lymphocytes there may be cells with three nuclei (Eastmond and Tucker, 1989; Rosefort et al., 2004).

The frequencies of binucleated and mononucleated cells with micronuclei in the treated cultures were compared with their respective controls by using one-way analysis of variance (ANOVA) followed by the one-tailed Dunnett post-hoc test. The same test was used to study the variability between donors and to compare the NDI of samples and controls. The equality of variances was assessed with Levene's test. A value of $p<0.05$ indicated significance.

Table 1 shows that BLM and d4T significantly lowered the NDI values at all concentrations tested. Low NDI values were also observed at the three highest concentrations of AZT and 3TC. All of the NRTIs tested signifi$\mathrm{c} \pm$ uclei in binucleated cells $(\mathrm{p} \leq 0.05)$. This increase was concentration-dependent for AZT and 3TC, except at the lowest concentration $(125 \mu \mathrm{g} / \mathrm{mL})$. In the case of d4T, the greatest increases in micronucleus frequency occurred at low concentrations and tended to decrease with increasing drug concentration.

AZT and 3TC did not significantly increase the frequency of micronuclei in mononucleated cells at any of the concentrations tested, possibly indicating that these two antiretrovirals are not aneugenic agents. In contrast, the lowest d4T concentration enhanced the frequency of micronuclei whereas the three highest concentrations had the opposite (negative) effect. The latter observation was probably related to the low NDI observed for the three highest $\mathrm{d} 4 \mathrm{~T}$ concentrations. 


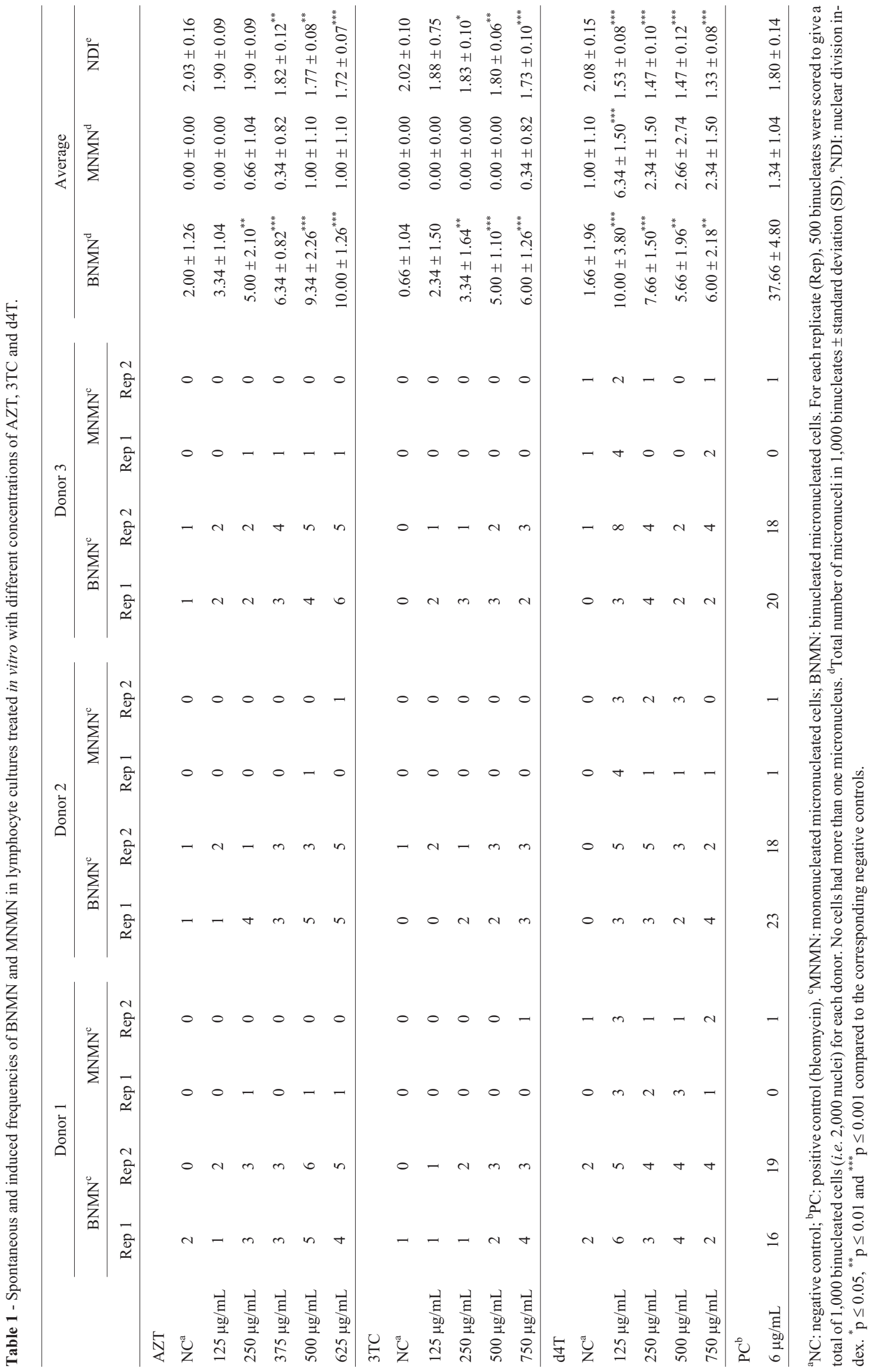


The aim of this study was to evaluate the clastogenic and/or aneugenic actions of the antiretroviral agents AZT, 3TC and $\mathrm{d} 4 \mathrm{~T}$ based on the formation of micronuclei in binucleated and mononucleated human lymphocytes (CBMN). As shown here, AZT and 3TC were genotoxic only in binucleated cells, which indicated that these NRTIs probably caused chromosomal breakage in human cells. AZT has been shown to induce micronuclei in cell cultures and animals (Gonzalez-Cid and Larripa, 1994; Agarwal and Olivero, 1997; Aruna and Jagetia, 2001; Von Tungeln et al., 2007). AZT also has clastogenic effects seen as the formation of micronuclei in human peripheral blood lymphocytes. In contrast, a negative response has been observed in the Salmonella typhimurium gene mutation assay, probably because these bacteria lack the enzyme activation required for AZT phosphorylation and activation seen in mammals (Wutzler and Thust, 2001). AZT incorporation into DNA induces mutations in the hypoxanthine-guanine phosphoribosyltransferase ( $\mathrm{Hprt}$ ) and thymidine kinase (Tk) genes. As previously reported, AZT also induces chromosomal aberrations, sister chromatid exchange (SCE) and telomere shortening in cultured cells (Olivero, 2007). In the wing somatic mutation and recombination test (SMART) both mutagenic and recombinogenic events contribute to the AZT-induced increase in the frequency of mutant clones, with $\sim 15 \%$ and $85 \%$ of the mutant spots being of mutational and recombinational origin, respectively (Guimarães et al., 2008).

3TC exerts a positive effect in the L5178Y $\mathrm{Tk}^{+/-}$ mouse lymphoma assay (Von Tungeln et al., 2007) and in clastogenicity assays (Physicians' Desk Reference, 2000), although an inconclusive effect was observed on mammalian gene mutation and SCE (Schilling et al., 1995; Physicians' Desk Reference, 2000). Indeed, 3TC has recently been classified as a weak inducer of SCE, chromosomal aberrations, and micronucleus formation in human peripheral lymphocytes in vitro (Bayram and Topaktas, 2008).

In addition to increasing the frequency of micronuclei in binucleated cells, d4T also affected mononucleated cells, possibly by causing chromosomal loss. This suggestion was based on a previous study that mincronucleus induction occurred exclusively in binucleated cells and was related to DNA breaks. Aneugenic drugs such as diethylstilbestrol, griseofulvin and vincristine sulphate increase frequencies of micronuclei in mononucleated and binucleated cells, whereas clastogens such as mitomycin C, bleomycin and doxorubicin increase the frequency of micronuclei only in binucleated cells (Migliore et al., 1989; Rosefort et al., 2004).

$\mathrm{d} 4 \mathrm{~T}$ is not genotoxic and does not cause cell transformation in vitro in most screening assays. According to the Physicians' Desk Reference, 2000. Healthcare Ser. 103 (online version). Micromedex Inc.Physicians' Desk Reference (2000), a weak clastogenic response has been observed in human peripheral lymphocytes in vitro and in

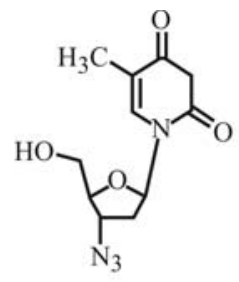

AZT

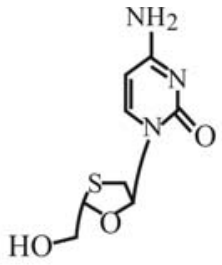

3TC

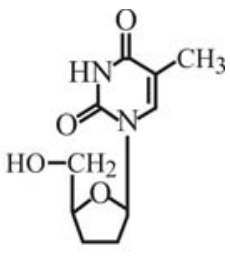

d4 T
Figure 1 - Chemical structure of zidovudine (AZT), lamivudine (3TC) and stavudine (d4T).

L5178Y cells. However, more recently, 3TC and d4T were identified as inducers of host cell DNA damage and mutations in two reporter genes, Hprt and Tk, using a cell cloning assay, which means that they may represent a risk of cancer (Carter et al., 2007). We have also observed that $3 \mathrm{TC}$ and $\mathrm{d} 4 \mathrm{~T}$ induce a large incidence of mutant spots in the SMART assay. Indeed, $\sim 86 \%$ of the genotoxicity of $3 \mathrm{TC}$ and $76 \%$ of that of $\mathrm{d} 4 \mathrm{~T}$ is linked to recombinogenic activities, which means that approximately $14 \%$ of the genotoxicity of $3 \mathrm{TC}$ and $24 \%$ of that of d4T can be imputed to the induction of mutational events (Franchi et al., 2009). Since in the SMART assay only two gene loci may express point mutations, we inferred that the mutagenicity observed was more probably related to chromosomal alterations. However, as far as we know, no aneugenic properties such as those observed here have previously been ascribed to d4T.

Structurally, the major difference among these three NRTIs resides in the 3' position of the 2'-deoxyribonucleoside, where AZT has an azido group, 3TC has a sulfur atom and $\mathrm{d} 4 \mathrm{~T}$ an unsaturated 2',3', dideoxyribose group (Figure 1). Despite the structural differences between AZT and 3TC, there were no significant divergences in their clastogenic effects, indicating that neither the azido nor the sulfur group interferes in the drugs' genotoxicity. The presence of 2',3', dideoxyribose instead of the azido group or sulfur atom seen in the other molecules ascribed a new property to $\mathrm{d} 4 \mathrm{~T}$, namely aneugenic activity. Although scoring mononucleated cells offers a new promise for the detection of micronuclei induced by aneugens, the unknown origin/status of these cells can adversely affect the reliability of the data (Fenech, 2000; Rosefort et al., 2004; Clare et al., 2006). In conclusion, the results of this study indicate the CBMN assay provides as useful means of quantitatively assessing the potential of NRTIs to disturb the human genome. Further analysis of the complexity of antiretroviral genotoxicity should reveal additional mechanisms that will allow the development of protective intervention strategies (Norppa and Falck, 2003; Olivero, 2007).

\section{Acknowledgments}

The authors thank Indústria Química de Goiás (IQUEGO), Goiânia, GO, Brazil for providing the samples of AZT, 3TC and d4T. 


\section{References}

Agarwal RP and Olivero OA (1997) Genotoxicity and mitochondrial damage in human lymphocytic cells chronically exposed to 3'-azido2', 3'dideoxythymidine. Mutat Res 390:223-231.

Aruna R and Jagetia GC (2001) Azidothymidine induces dose dependent increase in micronuclei formation in cultured HeLa cells. Pharmazie 56:492-500.

Bayram S and Topaktas M (2008) Confirmation of the chromosome damaging effects of lamivudine in in vitro human peripheral blood lymphocytes. Environ Mol Mutagen 49:328333.

Carter MM, Torres SM, Cook DL, McCash CL, Yu M, Walker VE and Walker DM (2007) Relative mutagenic potencies of several nucleoside analogs, alone or in drug pairs, at the Hprt and Tk loci of human TK6 lymphoblastoid cells. Environ Mol Mutagen 48:239-247.

Clare MG, Lorenzon G, Akhurst LC, Marzin D, van Delft J, Montero R, Botta A, Bertens A, Cinelli S, Thybaud V et al. (2006) SFTG international collaborative study on in vitro micronucleus test: II. Using human lymphocytes. Mutat Res 607:37-60.

Dobrovolsky VN, Mcgarrity LJ, Von Tungeln LS, Mittelstaedt RA, Morris SM, Beland FA and Heflich RH (2005) Micronucleated erythrocyte frequency in control and azidothymidine - Treated $T k+/+, T k+/-$ and $T k-/-$ mice. Mutat Res 570:227-235.

Eastmond DA and Tucker JD (1989) Identification of aneuploidy-inducing agents using cytokinesis-blocked human lymphocytes and an antikinetochore antibody. Environ Mol Mutagen 13:34-43.

Elhajouji A, Cunha M and Kirsch-Volders M (1998) Spindle poisons can induce polyploidy by mitotic slippage and micronucleate mononucleates in the cytokinesis-block assay. Mutagenesis 13:193-198.

Fenech M (2000) The in vitro micronucleus technique. Mutat Res 455:81-95.

Fenech M, Chang WP, Kirsch-Volders M, Holland N, Bonassi S and Zeiger E (2003) HUMN Project: Detailed description of the scoring criteria for cytokinesis-block micronucleus assay using isolated human lymphocyte cultures. Mutat Res 534:65-75.

Franchi LP, Pentiado NHGR, Silva RN, Guimarães NN, Jesuino RSA, Andrade HHR, Lehmann M and Cunha KS (2009) Mutagenic and recombinagenic effects of lamivudine and stavudine antiretrovirals in somatic cells of Drosophila melanogaster. Food Chem Toxicol 47:578-582.

Gonzalez-Cid M and Larripa I (1994) Genotoxic activity of azidothymidine (AZT) in in vitro systems. Mutat Res 321:113118.

Guimarães NN, Pereira KC, Andrade HHR, Lehmann M and Cunha KS (2008) Comparative analysis of genetic toxicity of AZT and ddI anti-retrovirals in somatic cells of Drosophila melanogaster. Environ Mol Mutagen 49:312-317.
Huang M and Jolicoeur P (1990) Characterization of the gag/fusion protein encoded by the defective Duplan retrovirus inducing murine acquired immunodeficiency syndrome. J Virol 64:5764-5772.

Kaur P and Singh R (2007) In vivo interactive effect of garlic oil and vitamin $\mathrm{E}$ against stavudine induced genotoxicity in Mus musculus. Indian J Exp Biol 45:807-811.

Kirsch-Volders M, Vanhauwaert A, De Boeck M and Decordier L (2002) Importance of detecting numerical versus structural chromosome aberrations. Mutat Res 504:137-148.

Migliore L, Nieri M, Amodio S and Loprieno N (1989) The human lymphocyte micronucleus assay: A comparison between whole-blood and separated-lymphocyte cultures. Mutat Res 227:167-172.

Mittelstaedt RA, Von Tungeln LS, Shaddock JG, Dobrovolsky VN, Beland FA and Heflich RH (2004) Analysis of mutations in the $T k$ gene of $T k^{+/}$mice treated as neonates with 3'-azido-3'-deoxythymidine (AZT). Mutat Res 547:63-69.

Norppa H and Falck GC (2003) What do human micronuclei contain? Mutagenesis 18:221-233.

Olivero OA (2007) Mechanisms of genotoxicity of nucleoside reverse transcriptase inhibitors. Environ Mol Mutagen 48:215-223.

Olivero OA, Anderson LM, Diwan BA, Haines DC, Harbaugh SW, Moskal TJ, Jones AB, Rice JM, Riggs CW, Logsdon D et al. (1997) Transplacental effects of 3'-azido-2',3'-dideoxythymidine (AZT): Tumorigenicity in mice and genotoxicity in mice and monkeys. J Natl Cancer Inst 89:1602-1608.

Physicians' Desk Reference (2000) Eletronic Library Medical Economics Company, Inc., Montvale, NJ.

Rosefort C, Fauth E and Zanki H (2004) Micronuclei induced by aneugens and clastogens in mononucleate and binucleate cells using the cytokinesis block assay. Mutagenesis 19:277-284.

Schilling BE, Nelson DR, Proctor JE, Diamond SS, Kaul S and Hawkins HC (1995) The nonclinical toxicologic profile of stavudine. Curr Ther Res 56:201-218.

Von Tungeln LS, Hamilton LP, Dobrovolsky VN, Bishop ME, Shaddock JG, Heflich RH and Beland FA (2002) Frequency of Tk and Hprt lymphocyte mutants and bone marrow micronuclei in $\mathrm{B} 6 \mathrm{C} 3 \mathrm{~F}(1) / T k+/$ - mice treated neonatally with zidovudine and lamivudine. Carcinogenesis 23:1427-1432.

Von Tungeln LS, Williams LD, Doerge DR, Shaddock JG, Mcgarrity LJ, Morris SM, Mittelstaedt RA, Heflich RH and Beland FA (2007) Transplacental drug transfer and frequency of $T k$ and Hprt lymphocyte mutants and peripheral blood micronuclei in mice treated transplacentally with zidovudine and lamivudine. Environ Mol Mutagen 48:258-269.

Wutzler P and Thust A (2001) Genetic risks of antiviral nucleoside analogues - A survey. Antiviral Res 49:55-74.

\section{Associate Editor: Catarina S. Takahashi}

License information: This is an open-access article distributed under the terms of the Creative Commons Attribution License, which permits unrestricted use, distribution, and reproduction in any medium, provided the original work is properly cited. 